\title{
Assessment of Water Quality in the Lakes Along Colentina River
}

\author{
Petra Ionescu ${ }^{1,2, a^{*}}$, Violeta-Monica Radu ${ }^{1, b}$, Elena Diacu ${ }^{2, c}$ \\ and Ecaterina Marcu ${ }^{1, d}$ \\ ${ }^{1}$ National Institute for Research and Development in Environmental Protection, 294 Spl. \\ Independentei, 6th District, 060031, Bucharest, Romania \\ ${ }^{2}$ University "Politehnica" of Bucharest, Faculty of Applied Chemistry and Materials Science, 1-7 \\ Polizu Str., 011061, Bucharest, Romania \\ apetraionescu2012@yahoo.ro, ${ }^{b}$ radumonica33@yahoo.com, celena_diacu@yahoo.co.uk, \\ dkatick_marcu@yahoo.com
}

Keywords: Colentina river, lakes, water quality, water pollution

\begin{abstract}
The purpose of this study is to evaluate the water quality in the lakes along Colentina River according to MO 161/2006. To achieve this goal, two sampling sections (entry and exit points) for each lake have been established, and the following indicators have been determined: $\mathrm{pH}$, water temperature, dissolved oxygen, biochemical oxygen demand, chemical oxygen demand, nitrites, nitrates and ammonium nitrogen, total nitrogen, orthophosphates, total phosphorus, electrical conductivity, filterable residue, chlorides, sulphates, calcium, magnesium and sodium. Following this study, the variation of the concentrations of determined indicators in the two sampling sections for each lake has been assessed, as well as the classification into quality classes according to the before mentioned order.
\end{abstract}

\section{Introduction}

The differential distribution of global water resources along with its unsustainable usage as well as the population growth have led in some regions to a social and ecologic collapse, posing a severe risk to the environment $[1,2]$.

Water quality is very important for human life, water being the major constituent of all living organisms, and thus, water quality assessment is a major objective in the management of water bodies [3].

Pollution of surface waters leads to severe effects on biosphere, affecting the aquatic life from microorganisms to insects, birds and fish, and also the health of animals and terrestrial plants [4-6].

Currently, under European Union law, many research studies are focused on finding ways to prevent and reduce pollution of aquatic ecosystems [7].

Despite the progress of the primary pollution control systems using municipal and industrial wastewater treatments, secondary pollution such as eutrophication has continued to deteriorate lately, becoming a significant problem for the biodiversity of aquatic ecosystems [8-10].

The process of eutrophication is generally understood as a nutrient enrichment of water bodies (especially with chemical forms of nitrogen and phosphorus) [11] that can determine the production of algae and superior plants, and thus the production of biomass, leading to an increased turbidity and in some cases to an increased odor of water $[12,13]$. Algal development affects water clarity and dissolved oxygen concentration, such phenomena being accompanied by the disappearance of aquatic fauna and finally, by the formation of swamps [14].

The lakes are open systems whose physicochemical and dynamic characteristics are influenced by the synergistic action of several factors [15], one of them being represented by the climate changes [16].

There are numerous natural and artificial lakes around Bucharest that have been used for economic and also recreational purposes. The Colentina River has a length of around $101 \mathrm{~km}$ from source to discharge, of which approx. $37.4 \mathrm{~km}$ being situated within the area of Bucharest city. The water from this river is primary used for irrigations and fishery, and also for direct consumption. 
There are several anthropic lakes on the Colentina River route, including Mogosoaia Lake, Herastrau and Pantelimon Lakes.

The purpose of this study was to evaluate the water quality of these three rivers from the physicochemical point of view.

\section{Materials and Methods}

\section{Samples}

The water samples have been collected from two sections: entry point (Section I) and exit point (Section II) of each lake, according to sampling standards [17]. The samples have been collected from approximately $30 \mathrm{~cm}$ below water level and stored in plastic bottles, keeping them at $4^{0} \mathrm{C}$ until being analyzed.

\section{Reagents and quality assurance}

Table 1 Analytical techniques applied for determination of physicochemical parameters [3]

\begin{tabular}{|c|c|c|}
\hline Parameter & Abbreviation & Applied analytical techniques \\
\hline \multicolumn{3}{|c|}{ Thermal regime and acidification } \\
\hline Temperature & $\mathrm{T}$ & thermometer \\
\hline $\mathrm{pH}$ & $\mathrm{pH}$ & pH-meter \\
\hline \multicolumn{3}{|c|}{ Salinity } \\
\hline Electrical Conductivity & $\mathrm{EC}$ & conductivity meter \\
\hline Filterable residue & TDS & gravimetric method \\
\hline Chlorides & $\mathrm{Cl}^{-}$ & titrimetric method \\
\hline Sulphates & $\mathrm{SO}_{4}{ }^{2-}$ & gravimetric method \\
\hline Calcium & $\mathrm{Ca}^{2+}$ & titrimetric method \\
\hline Magnesium & $\mathrm{Mg}^{2+}$ & titrimetric method \\
\hline Sodium & $\mathrm{Na}^{+}$ & atomic absorption spectrometry \\
\hline \multicolumn{3}{|c|}{ Oxygen regime } \\
\hline Dissolved oxygen & OD & Winkler titration, DO meter \\
\hline Chemical oxygen demand & COD & permanganate titration \\
\hline $\begin{array}{l}\text { 5-days biochemical oxygen } \\
\text { demand }\end{array}$ & BOD & incubation, Winkler titration \\
\hline \multicolumn{3}{|c|}{ Nutrients } \\
\hline Ammonium-nitrogen & $\mathrm{NH}_{4}-\mathrm{N}$ & sodium nitroprusside, spectrophotometry \\
\hline Nitrite-nitrogen & $\mathrm{NO}_{2}-\mathrm{N}$ & 4-aminobenzene sulphonamide, spectrophotometry \\
\hline Nitrate-nitrogen & $\mathrm{NO}_{3}-\mathrm{N}$ & sulphosalicylic acid, spectrophotometry \\
\hline Total nitrogen & TN & titrimetric method \\
\hline Orthophosphates & $\mathrm{PO}_{4}-\mathrm{P}$ & spectrophotometry \\
\hline Total phosphorus & $\mathrm{TP}$ & peroxydisulphate oxidation, spectrophotometry \\
\hline
\end{tabular}

The following indicators have been assessed for the evaluation of water quality: $\mathrm{pH}$, water temperature, dissolved oxygen, biochemical oxygen demand, chemical oxygen demand, nitrites, nitrates and ammonium nitrogen, total nitrogen, orthophosphates, total phosphorus, electrical conductivity, filterable residue, chlorides, sulphates, calcium, magnesium, and sodium (Tabel 1).

All reagents used for the determination of the above mentioned indicators were of analytical purity and their determinations were performed using standardized methods of analysis. 


\section{Results and discussions}

The quality assessment of monitored waters was performed using the M.O. no. 161/2006 [18] from Romanian Legislation. Table 2 presents quality classes of monitored indicators for the two sampling sections: entry (Section I) and exit (Section II) points of each evaluated lake.

Table 2 Framing of monitored quality indicators in quality classes for the three lakes

\begin{tabular}{|c|c|c|c|c|c|c|}
\hline \multirow{4}{*}{ Parameter } & \multirow{2}{*}{\multicolumn{2}{|c|}{$\begin{array}{c}\text { Mogosoaia Lake } \\
\text { Section }\end{array}$}} & \multirow{2}{*}{\multicolumn{2}{|c|}{$\begin{array}{c}\text { Herastrau Lake } \\
\text { Section }\end{array}$}} & \multirow{2}{*}{\multicolumn{2}{|c|}{$\begin{array}{c}\text { Pantelimon Lake } \\
\text { Section }\end{array}$}} \\
\hline & & & & & & \\
\hline & I & II & I & II & I & II \\
\hline & \multicolumn{6}{|c|}{ Quality Class according MO 161/2006 } \\
\hline $\mathrm{T}$ & \multirow{2}{*}{\multicolumn{6}{|c|}{ not standardized }} \\
\hline EC & & & & & & \\
\hline $\mathrm{pH}$ & \multicolumn{6}{|c|}{$7.22-7.91$} \\
\hline DO & $\mathrm{I}$ & $\mathrm{I}$ & $\mathrm{I}$ & $\mathrm{I}$ & $\mathrm{I}$ & $\mathrm{I}$ \\
\hline BOD & II & II & II & I & II & I \\
\hline COD & II & II & II & II & II & II \\
\hline $\mathrm{NH}_{4}-\mathrm{N}$ & II & II & II & II & II & II \\
\hline $\mathrm{NO}_{2}-\mathrm{N}$ & II & I & IV & IV & IV & IV \\
\hline $\mathrm{NO}_{3}-\mathrm{N}$ & I & I & I & I & I & I \\
\hline $\mathrm{TN}$ & $\mathrm{I}$ & $\mathrm{I}$ & $\mathrm{I}$ & $\mathrm{I}$ & $\mathrm{I}$ & $\mathrm{I}$ \\
\hline $\mathrm{PO}_{4}-\mathrm{P}$ & IV & IV & IV & IV & II & III \\
\hline $\mathrm{TP}$ & II & II & II & II & I & I \\
\hline TDS & $\mathrm{I}$ & $\mathrm{I}$ & $\mathrm{I}$ & $\mathrm{I}$ & $\mathrm{I}$ & $\mathrm{I}$ \\
\hline $\mathrm{Cl}^{-}$ & II & II & II & II & III & II \\
\hline Sulphates & I & I & I & I & I & I \\
\hline $\mathrm{Ca}^{2+}$ & I & I & I & I & I & I \\
\hline $\mathrm{Mg}^{2+}$ & I & I & I & I & I & I \\
\hline $\mathrm{Na}^{+}$ & II & II & II & II & II & II \\
\hline
\end{tabular}

As an overall assessment, the investigations of Mogosoaia, Pantelimon and Herastrau lakes have led to a general classification of the monitored sections as quality classes I-IV, according to MO 161/2006. The evaluation of nitrites concentration in the Mogosoaia and Herastrau lakes and orthophosphates concentration in Herastrau and Pantelimon lakes resulted in a classification of monitored sections as quality class IV, according to the above mentioned order.

From the graphical representation of the nutrients variation in the monitored lakes (Fig. 1) the downward trend in concentrations of $\mathrm{NH}_{4}-\mathrm{N}$ in both sampling sections of the three monitored lakes can be observed. The $\mathrm{NO}_{2}-\mathrm{N}$ concentration recorded a maximum of $0.28 \mathrm{mg} / \mathrm{L}$ in sampling section II of Pantelimon Lake.

The concentration of total nitrogen in sections monitored varies as: Mogosoaia L.> Herastrau L.> Pantelimon L. Total phosphorus concentration in the first section varies as follows: Herastrau L. > Mogosoaia L. > Pantelimon L. (Fig. 1a) and concentration determined in the second section is as follows: Mogosoaia L. > Herastrau L. > Pantelimon L. (Fig. 1b). 


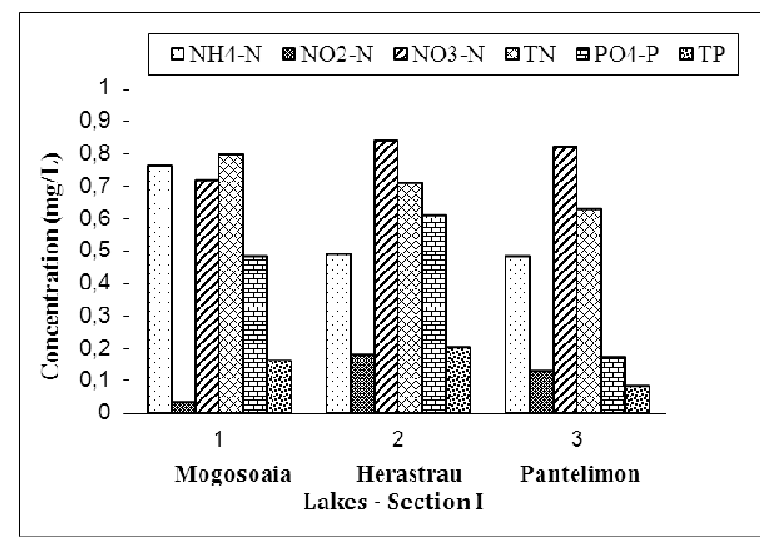

(a)

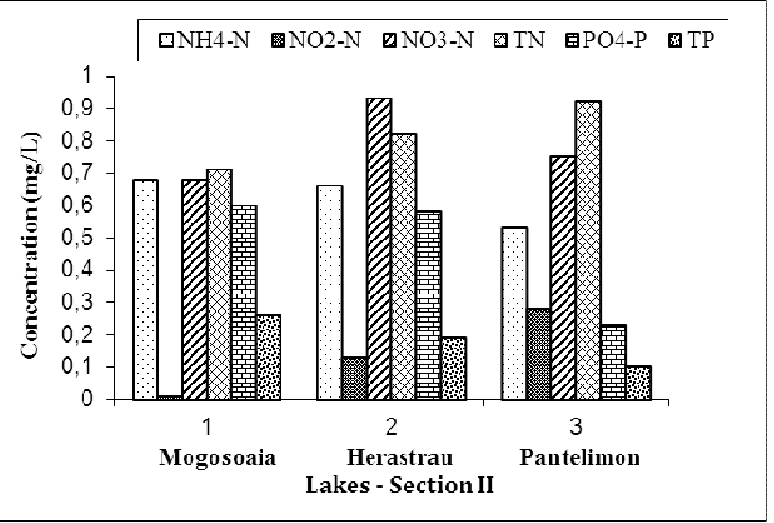

(b)

Fig. 1 Variation of nutrients in the monitored lakes for the two sections: entry point-Section I (a) and exit point -Section II (b)

Following the analysis of the oxygen variation (Fig. 2), the variation of the concentration of dissolved oxygen, biochemical oxygen demand and chemical oxygen demand in both sections is as follows: Mogosoaia L. $<$ Herastrau L. $<$ Pantelimon L. As for the specific indicators for assessing salinity, higher values were found in section I than in section II, for all the three lakes.

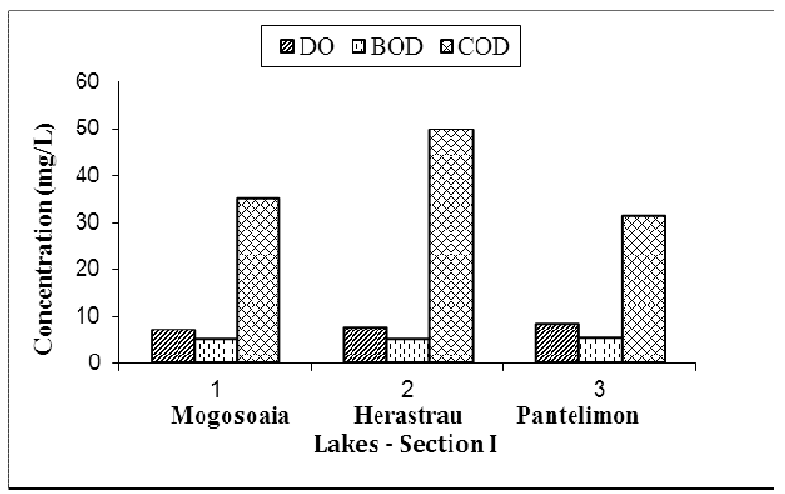

(a)

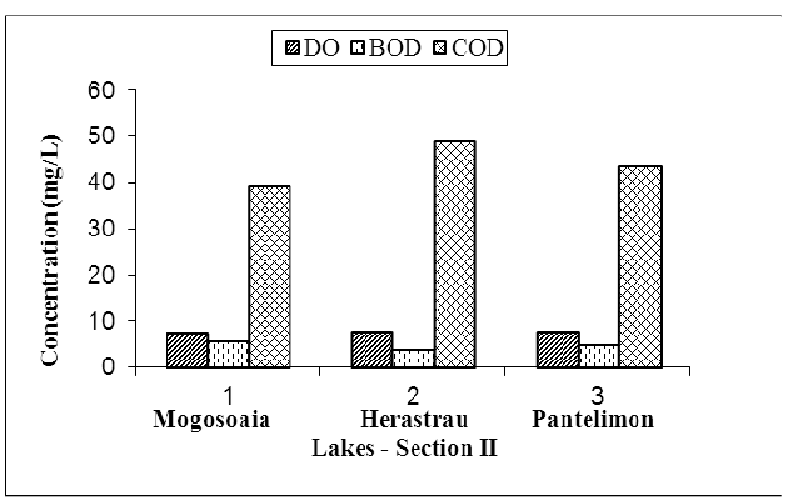

(b)

Fig. 2 Variation of oxygen for the two sections: entry point - Section I (a) and exit point - Section II (b)

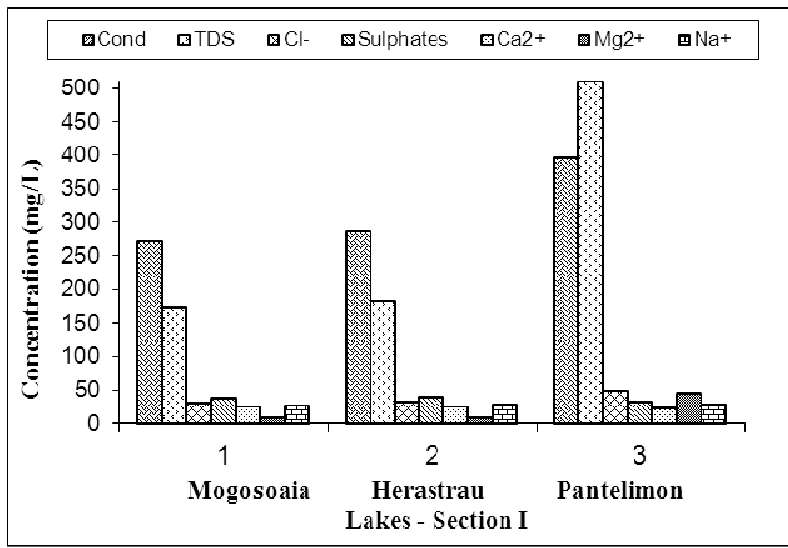

(a)

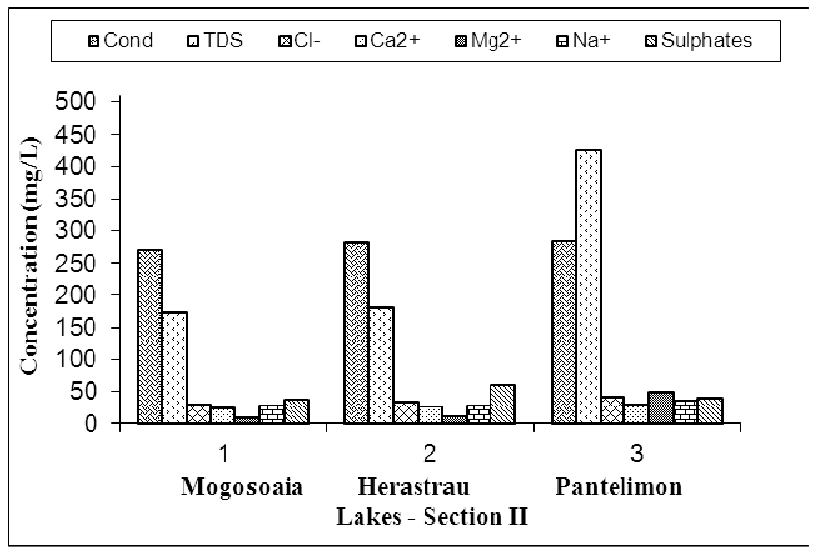

(b)

Fig. 3 Variation of salinity specific indicators for the two sections: entry point - Section I (a) and exit point - Section II (b) of each lake 
Quality indicators specific to salinity, such as calcium, magnesium, sodium and potassium, are substances of natural origin and are not related to pollution. Fig. 3 shows approximately similar values for Mogosoaia and Herastrau lakes, and higher values for Pantelimon Lake.

\section{Conclusions}

Based on the assessed quality parameters, their framing into quality classes for the two sections of each evaluated lake has been established. It has been found that the monitored indicators are generally included in the quality classes I and II according to MO 161/2006, although the concentration of nitrites in Mogosoaia and Herastrau lakes as well as the concentration of orthophosphates in the Herastrau and Pantelimon lakes are specific to values of quality class IV according to the above mentioned order.

For the upstream lakes (Mogosoaia and Herastrau), higher values for ammonium and orthophosphates, and lower values for nitrates, total nitrogen, filterable residue, chlorides and magnesium than the ones from Pantelimon Lake have been recorded. Other quality indicators had similar values for the 6 sampling points.

Following this study, Mogosoaia and Herastrau have been classified as eutrophic-hypertrophic type lakes and Pantelimon Lake has been classified as meso-eutrophic type.

Acknowledgements: The authors are grateful to the general management and colleagues from INCDPM for their valuable assistance and suggestions. This research has been partially financed by Project SOP HRD - PERFORM 159/1.5/S/138963.

\section{References}

[1] N.J. Houser, W.B. Richardson, Nitrogen and phosphorus in the Upper Mississippi River: transport, processing, and effects on the river ecosystem, Hydrobiologia. 640 (2010) 71-88.

[2] S. Chandra, A. Singh, P.K. Tomar, Assessment of Water Quality Values in Porur Lake Chennai, Hussain Sagar Hyderabad and Vihar Lake Mumbai, India. Chem. Sci. Trans. 1 (2012) 508-515.

[3] V.-M. Radu, P. Ionescu Gy. Deák, A.A. Ivanov, E. Diacu, Multivariate Statistical Analysis for Quality Assesment of Aquatic Ecosystem on the Lower Danube, Journal of Environmental Protection and Ecology. 15 (2014) 412-424.

[4] F. Zhang, J. Liu, Z. Yang, Y. Li, Ecosystem health assessment of urban rivers and lakes -Case study of "the six lakes" in Beijing, China, Frontiers of Environmental Science \& Engineering in China. 2 (2008) 209-217.

[5] N.A. Cirerol, F. Comín, J. Herrera-Silveira, Nitrogen and phosphorus budgets for the Yucatán littoral: An approach for groundwater management, Environmental Monitoring and Assessment. 172 (2011) 493-505.

[6] P. Ionescu, V.-M. Radu, Gy. Deák, E. Diacu, Distribution, Partition and Fluxes of Trace Heavy Metals in the Lower Danube River, REV. CHIM. (Bucharest). 65 (2014) 1092-1095.

[7] V.-M. Radu, E. Diacu, A. Ivanov, Gy Deák, Gas-Chromatographic Technique for the Analysis of Floculant PRAESTOL Content in Surface Waters, REV. CHIM. (Bucharest). 65(2014) 757-761.

[8] S. Naeher, R.H. Smittenberg, A. Gilli, E.P. Kirilova, A.F. Lotter, C.J Schuber, Impact of recent lake eutrophication on microbial community changes as revealed by high resolution lipid biomarkers in Rotsee (Switzerland), Organic Geochemistry. 49 (2012) 86-95. 
[9] A. Hussain Mir, B. Mushtaq, R. Ara Wani, A. Jehangir, A.R. Yousuf, Physico-chemical Characterization of Sediments of River Jhelum around Srinagar, Kashmir, India, International Journal of Environment and Bioenergy. 5 (2013) 49-61.

[10] T. N. Minh Luu, J. Garnier, G. Billen, T. P. Quynh Le, J. Nemery, D. Orange, L. Anh Le, N, P, Si budgets for the Red River Delta (northern Vietnam): how the delta affects river nutrient delivery to the sea, Biogeochemistry. 107 (2012) 241-259.

[11] M.J. Bernot, R.J. Bernot, J.T. Morris, Nutrient cycling relative to d15N and d13C natural abundance in a coastal wetland with long-term nutrient additions, Aquat. Ecol. 43 (2009) 803-813

[12] J.D. Chaffin, T.B. Bridgeman, D.L. Bade, Nitrogen Constrains the Growth of Late Summer Cyanobacterial Blooms in Lake Erie, Advances in Microbiology. 3 (2013) 16-26

[13] X. Mao, C. Wang, X. Wei, Q. Chen, The distribution of chlorophyll-a and its' correlation with related indicators in the Ulansuhai Lake, China, Journal of Environmental Accounting and Management. 2 ( 2014) 121-129.

[14] H. Pathak, D. Pathak, Eutrophication: Impact of Excess Nutrient Status in Lake Water Ecosystem, J. Environ. Anal. Toxicol. 2 (2012) 1-5.

[15] C.E. Telteu, L. Zaharia, Morphometrical and dynamical features of the South Dobrogea lakes, Romania, Procedia Environmental Sciences. 14 (2012) 164-176.

[16]L. Arvola, K. Salonen, J. Keskitalo, T. Tulonen, M. Jarvinen, J. Huotari, Plankton metabolism and sedimentation in a small boreal lake - a long-term perspective, Boreal Environment Research. 19(2014) 83-96.

[17] ISO 5667-4:2000, Water quality - Sampling - Part 4: Guidance on sampling from lakes, natural and man-made.

[18] Ministry Order No. 161 of 16 February 2006 approving the Norms on surface water quality classification to determine the ecological status of water bodies. 